\title{
Toksoplazma Koryoretinitine Bağlı Geniş Seröz Makula Dekolmanı: Olgu Sunumu
}

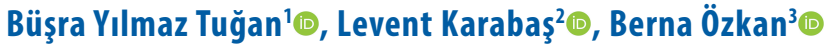

'İzmit Seka Devlet Hastanesi, Oftalmoloji, Kocaeli, Türkiye

${ }^{2}$ Kocaeli Üniversitesi, Oftalmoloji, Kocaeli, Türkiye

${ }^{3}$ Acıbadem Mehmet Ali Aydınlar Üniversitesi, Oftalmoloji, İstanbul, Türkiye

Büşra Yılmaz Tuğan, Uzm. Dr. Levent Karabaş, Prof. Dr. Berna Özkan, Prof. Dr.

\section{İletişim:}

Uzm. Dr. Büşra Y.lmaz Tuğan İzmit Seka Devlet Hastanesi, Oftalmoloji, Kocaeli, Türkiye

Tel: +905333513399

E-Posta: busrayilmaz87@hotmail.com

Gönderilme Tarihi : 09 Ağustos 2018

Revizyon Tarihi : 15 Aralk 2018

Kabul Tarihi : 18 Aralık 2018
ÖZET

Toxoplasma gondii koryoretinite sebep olabilen zorunlu intraselüler parazittir. Çoğunlukla kendine sınırlı bir hastalık olmasına rağmen optik sinir ya da maküla tutulumuna ve/veya ağır vitreus inflamasyonuna sekonder görme keskinliğini azaltabilir. Enfeksiyonun 'klasik' bulgusu pigmente koryoretinal skardır. Kenarında tüysü beyaz, nekrotizan retinokoroidit odağı görülebilir. Biz burada hızlı ve uygun bir tedavi sonucu anatomik ve fonksiyonel başarı elde ettiğimiz geniş seröz maküla dekolmanı ile komplike olmuş bir toksoplazma koyoretiniti olgusunu sunmayı amaçladık.

Anahtar sözcükler: Seröz makula dekolmanı, toxoplazma koryoretiniti, retinokoroidit

\section{LARGE SEROUS MACULAR DETACHMENT RELATED TO TOXOPLASMIC CHORIORETINITIS: A CASE REPORT}

\section{ABSTRACT}

Toxoplasma gondii is an obligate intracellular parasite, which can cause chorioretinitis. Although it is usually a selflimited disease, it may reduce vision secondary to the optic nerve or macular involvement and/or severe vitreous inflammation. The 'classic' sign of the infection is pigmented chorioretinal scar. The fluffy white nidus of the necrotizing retinochoroiditis can be seen adjacent to it. Here, we aimed to present a toxoplasmic chorioretinitis case complicated with a large serous macular detachment that we achieved anatomical and functional success as a result of prompt and suitable therapy.

Keywords: Serous macular detachment, toxoplasmic chorioretinitis, retinochoroiditis

$\mathbf{T}$ oxoplasma gondii koryoretinite sebep olabilen zorunlu intraselüler parazittir (1). Çoğunlukla kendine sınırlı bir hastalık olmasına rağmen optik sinir ya da maküla tutulumuna ve/veya ağır vitreus inflamasyonuna sekonder görme keskinliğini azaltabilir. İmmünkompetan hastada tedavi ile ya da tedavisiz aktif retinokoroiditin 1 ay ile 2 ay arasında spontan rezolüsyonü görülebilir (2). Genel olarak oküler toksoplazmoziste sistemik tedavi endikasyonu 2 optik diskten büyük retina zonunda 3+ ve daha fazla vitreus hücresiyle ilişkili aktif lezyon olmasıdır (3). Biz de kliniğimize başvuran büyük seröz maküla dekolmanlı toksoplazmik koryoretinit vakasını sunmayı amaçladık.

\section{Olgu sunumu}

26 yaşında kadın hasta 2 gün önce azalan görme keskinliği ve uçuşan siyah noktalar şikayetiyle Mayıs 2015 tarihinde Kocaeli Üniversitesi Oftalmoloji Departmanına 
başvurdu. Hastanın sağ gözünde görme keskinliği 20/60 idi. Yarıklı lamba muayenesinde ön kamarada 1+ hücre, fundus muayenesinde maküla inferotemporalinde koryoretinal skar ve makulada seröz retina dekolmanı vardı. Optik koherans tomografide (OKT) sağ gözde seröz makula dekolmanı gözlendi (Şekil 1b). Hastanın infeksiyöz markerlarından Toxoplazma Ig M negatif iken Toxoplazma Ig G, CMV Ig G ve Rubella Ig G pozitif olup Toxoplazma Ig $\mathrm{G}$ aviditesi yüksekti (0.63). Hastaya pirimetamin (3 gün boyunca $50 \mathrm{mg}$ yükleme dozu ve sonrasında günlük $25 \mathrm{mg}$ ) ile folinik asit ( $5 \mathrm{mg}$ haftada $3 \mathrm{kez}$ ) ve trimetoprim-sulfametaksazol (TMP-SMZ) (2x160mg/800 mg/gün) kombinasyon tedavisi başlandı.

Tedavinin altıncı gününde hastanın görme keskinliği 20/32 düzeyinde idi. Yarıklı lamba muayenesinde ön kamarada reaksiyon yoktu ve fundus muayenesinde seröz makula dekolmanı azalmıştı. OKT'de seröz dekolmanın azaldığı görüldü. Tedavi başlandıktan 18 gün sonra tedaviye oral prednizolon $32 \mathrm{mg}$ eklendi. 1 hafta sonrasında doz 16 mg'a düşüldü.

Tedavinin dördüncü haftasında görme keskinliğinin 20/60 dan 20/20'ye yükseldiği, ön kamara reaksiyonunun olmadığı ve subretinal sıvının rezorbe olduğu görüldü. Yapılan OKT de subretinal sıvı yoktu (Şekil 2b). Tedavinin altıncı haftasında pirimetamin tedavisi sonlandırılıp iki hafta 16 mg kullanılan prednizolon 8 mg'a düşürüldü.

Hasta ikinci ayda muayene edildiğinde görme keskinliği yine 20/20 idi, ön kamara reaksiyonu ve subretinal sIVISI yoktu, skar mevcuttu. Steroid tedavisi kesilip TMP-SMZ azaltılıp (1x160mg/800 mg/gün) haftada üç kez profilaktik olarak devam edildi.

\section{Tartışma}

Toksoplazma koryoretinitinde sıklıkla değiş̧miş görme keskinliği ile ilişkili olabilecek uçuşmalar görülür. Enfeksiyonun 'klasik' bulgusu olan pigmente koryoretinal skar kenarında tüysü beyaz, nekrotizan retinit ya da retinokoroidit odağı görülür. Retinit odağı genellikle tam kattır ancak Friedmann and Knox (4)'un tariflediği gibi iç ya da dış retina katlarının sınırlı şekilde etkilendiği de görülür. Etkilenen retinanın boyutu ve kalınlığıyla ilişkili olarak, üzerindeki vitreus ve yakınındaki koroid değişken derecelerde etkilenir. Geniş, tam kat lezyonlar klasik 'sisteki far' bulgusuna yol açarak daha ciddi vitreus inflamasyonuna yol açmaya meyillidir (2). Atipik prezentasyonlar görülebilse de patogenez ve tedavi aynıdır (5).
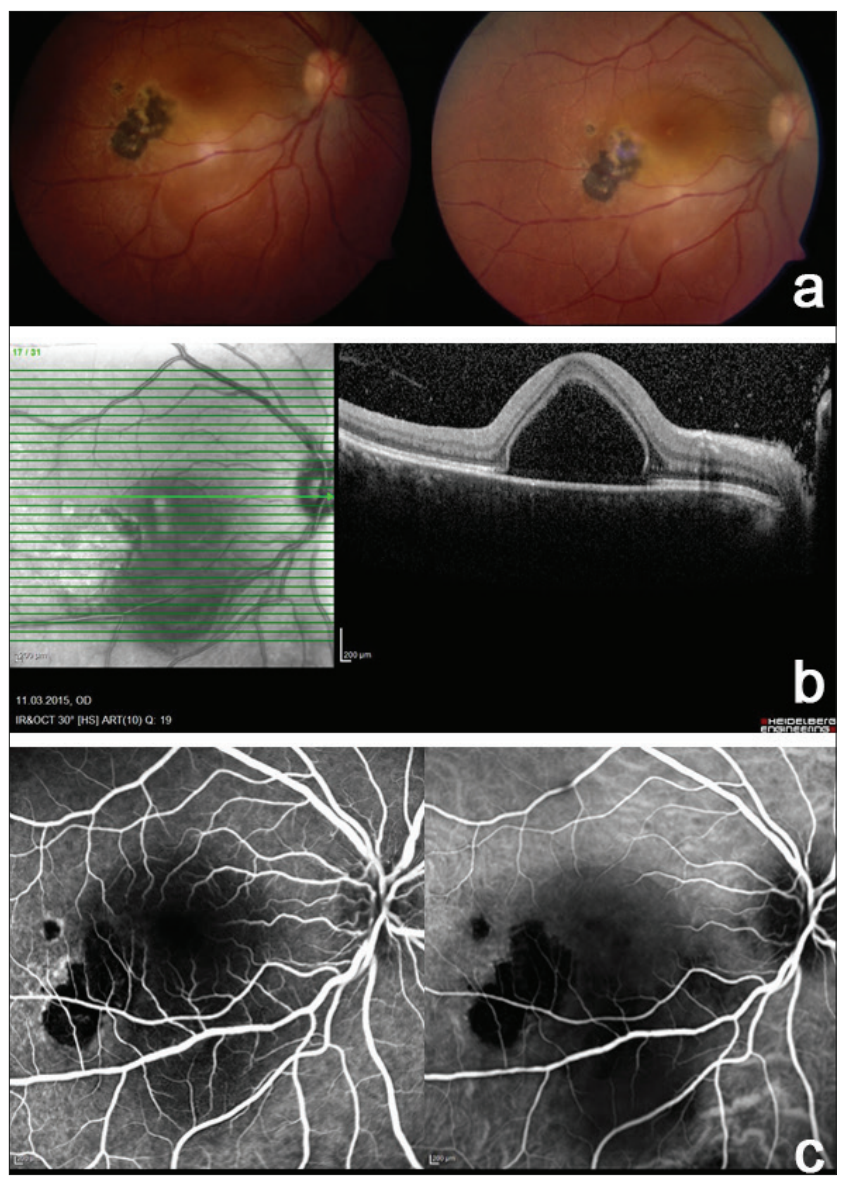

Şekil 1. Hasta başvurduğunda (a) fundus fotoğrafı, (b) OKT görüntüsü, (c) FFA görüntüsü.
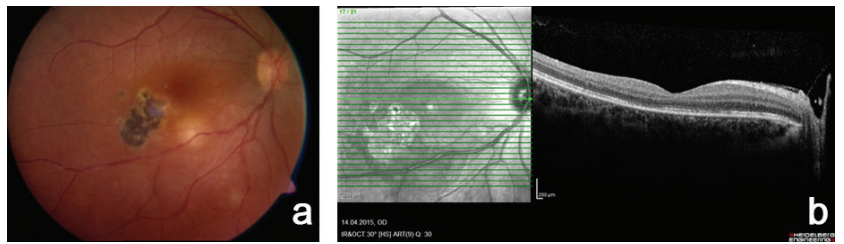

Şekil 2. Tedavini dördüncü haftasında (a) fundus fotoğrafı, (b) OKT görüntüsü.

OKT'de subretinal sıvının aktif oküler toksoplazmoziste daha sık görüldüğü çalışmalarda gösterilmiştir $(6,7)$. Ouyang ve arkadaşlarının çalışmasında tüm aktif oküler toksoplazmosiz olan gözlerde OKT'de subretinal sıvı prevalansı \%51.3 olarak bulunmuştur. Aynı çalışmada subretinal sıvının yerinin aktif retinitin bulunduğu alanla büyük ölçüde ilişkili olduğu ve bu nedenle sıvı birikiminin retinit ve ya retinal nekroza sekonder artmış vasküler geçirgenliğe bağlı olduğu vurgulanmıştır (8).

Literatürde unilateral akut idiopatik makülopati olup retinit alanında minimal subetinal sıvı olan ve edinsel toksoplazma retiniti tanısı alan bir olgu olduğu görülmüştür 
(9). Biz fundus muayenesinde maküla inferotemporalinde koryoretinal lezyon ve seröz makula dekolmanı olan bir hasta deneyimledik. Olgumuzda görme azalması makulanın direkt tutulmasına bağlı olmayıp seröz dekolmana bağlıydı. Seröz dekolman düzeldiğinde görme keskinliği de 20/20'ye yükseldi.

Toksoplazmik retinokoroiditin düzelmesiyle atrofik, iyi sınırlı retinal skar oluşur. Bu skar genelde başlangıçta etkilenen retina alanından daha küçüktür, skardaki pigmentasyon ve koroidal atrofi aktif fazdaki retina pigment epitel

\section{Kaynaklar}

1. Perkins ES. Ocular toxoplasmosis. Br J Ophthalmol 1973;57:1-17. [CrossRef]

2. Holland, GN., O'Connor, GR., Belfort, R., Junior; Remington, JS. Toxoplasmosis. In: Pepose, JS.; Holland, GN.; Wilhelmus, KR., editors. Ocular Infection \& Immunity. St. Louis: Mosby; 1996. p. 1183-223.

3. Holland GN, Lewis KG. An update on current practices in the management of ocular toxoplasmosis. Am J Ophthalmol. 2002;134:102-14. [CrossRef]

4. Friedmann CT, Knox DL. Variations in recurrent active toxoplasmic retinochoroiditis. Arch Ophthalmol. 1969; 81:481-93. [CrossRef]

5. Holland GN. Ocular toxoplasmosis: a global reassessment. Part II: disease manifestations and management. Am J Ophthalmol. 2004;137:1-17.

6. Diniz B, Regatieri C, Andrade R, Maia A. Evaluation of spectral domain and time domain optical coherence tomography findings in toxoplasmic retinochoroiditis. Clin Ophthalmol 2011;5: 645-50. [CrossRef]

7. Foster CS, Vitale AT. Diagnosis and Treatment of Uveitis JP Medical Ltd. 2013 hasarının derecesiyle ilişkilidir. Geleneksel tedavi sulfadiazine, primetamin ile folinik asit, klindamisin ve TMP-SMZ içerir. Primetamin ve sulfadiazinin sinerjistik kombinasyonu en sık kullanılan tedavidir $(10,11)$. Son zamanlarda azitromisin ve atovakuon gibi antimikrobiyaller başarıyla kullanılmıştır $(12,13)$.

Sonuç olarak, toksoplazmik koryoretinite sekonder seröz maküla dekolmanı gelişebilir. Bu seröz dekolmanın toxoplazma retiniti tedavi edildiğinde tamamen düzelme gösterdiği gözlenmiştir.

8. Ouyang Y, Li F, Shao Q, Heussen FM, Keane PA, Stübiger N, Sadda SR, Pleyer U. Subretinal fluid in eyes with active ocular toxoplasmosis observed using spectral domain optical coherence tomography. PLoS One 2015:26;10:e0127683. [CrossRef]

9. Lieb DF, Scott IU, Flynn HW Jr, Davis JL, Demming SM. Acute acquired toxoplasma retinitis may present similarly to unilateral acute idiopathic maculopathy. Am J Ophthalmol. 2004;137:940-2. [CrossRef]

10. Lieb DF, Scott IU, Flynn HW Jr, Davis JL, Demming SM. Acute Acquired Toxoplasma Retinitis May Present Similarly to Unilateral Acute Idiopathic Maculopathy . Am J Ophthalmol 2004;137:940-42. [CrossRef]

11. Engstrom RE, Holland GN, Nussenblatt RB, Jabs DA. Current Practices in the Management of Ocular Toxoplasmosis. Am J Ophthalmol. 1991;111:601-10. [CrossRef]

12. Rothova A, Bosch-Driessen LE, van Loon NH, Treffers WF. Azithromycin for ocular toxoplasmosis. Br J Ophthalmol. 1998;82:1306-8. [CrossRef]

13. Pearson PA, Piracha AR, Sen HA, Jaffe GJ. Atova-quone for the treatment of toxoplasma retinochoroiditis in immunocompetent patients. Ophthalmology. 1999;106:148-53. [CrossRef] 